\title{
Balancing skills in the digital transformation era: The future of jobs and the role of higher education
}

Industry and Higher Education

(C) The Author(s) 2021

Article reuse guidelines: sagepub.com/journals-permissions DOI: $10.1177 / 09504222211029796$ journals.sagepub.com/home/ihe

\author{
Vera G. Goulart \\ Bandtec Digital School, Brazil \\ Lara Bartocci Liboni \\ University of São Paulo, Brazil \\ Luciana Oranges Cezarino $(1)$ \\ Federal University of Uberlândia, Brazil
}

\begin{abstract}
Developing human resources and matching job profiles are essential tasks to promote economic and social growth. The technology-related job market has undergone significant changes over recent years, mainly due to technological advances that have pushed industry toward new demands for skilled professionals. This change in required skills and competencies has led to a gap between what companies need and the professional profiles that are available in the job market. Technology companies are often unable to find an employee who meets the required profile, resulting in financial loss and extra training expenses. It is therefore essential that higher education in technology is reconsidered to address job market demands. Thus the goal of this work is to evaluate the relationship between the professional profile required by information technology (IT) companies and what students are taught on IT-related programs in higher education institutions (HEls). The authors adopt a systemic perspective in three different qualitative approaches. They crosscheck and link data on educational curricula acquired from interviews with IT human resource managers (HRMs) and student focus groups. The analysis reveals that HEls must go beyond the transfer of knowledge and technical qualification in IT, promoting a comprehensive education that incorporates personal development goals, with a focus on developing social and emotional skills. The study focuses on the emerging economy of Brazil and presents findings from which other developing countries can learn. The results reveal the critical role of soft skills in the professional development and employability of students and the associated challenge for technical education. In conclusion, the authors also highlight the importance of partnerships between HEls and HRMs as a fundamental strategy to fulfill the current skills gap.
\end{abstract}

\section{Keywords}

Higher education, information technology, labor market, skills, soft skills

Technology development has intensified the role of innovation in organizations, reinforcing competition and co-operation as simultaneous needs. In this context, the increasing complexity of new high-tech solutions and innovations is resulting in a demand from employers for novel ways of thinking and new skill sets.

The IT industry is currently one of the most dynamic and innovative sectors, and has increased in importance with the new paradigm of digital transformation. The sector needs skilled professionals to work on the frontier of new technologies and industrial challenges. While the supply side of the job market adapts to changing demand, the adjustment does not always occur at the pace the demand side requires. Technology companies often fail to find adequate professional profiles, incurring financial loss and

\section{Corresponding author:}

Luciana Oranges Cezarino, Department of Management, Ca' Foscari University of Venice, San Giobbe, Cannaregio 873, Fondamenta San Giobbe, 30121 Venice, Italy.

Email: luciana.cezarino@unive.it 
process inefficiencies as well as extra expense for staff training (Goulart et al., 2021).

Organizations and stakeholders at all levels are committed to developing frameworks and undertaking research to better understand the new professional skills that are required (Garcia-Esteban and Jahnke, 2020) in the IT job market (Kurbanov et al., 2020). The professional profile is being transformed in the field of IT, and this transformation is mainly characterized by the new skills and qualifications that an employee has to develop. In this sense, higher education plays a vital role in leveraging the development of the necessary professional skills (Kurbanov et al., 2020). Therefore, it is fundamental for both companies and higher education institutions (HEIs) to understand the nature of the required professional profile (Pineda-Herrero et al., 2018). However, there is a gap between what the market sees as relevant and what HEIs understand to be critical (Goulart et al., 2021). Decision-making, language skills and theoretical and practical knowledge are among the skills highlighted as critical to the development of IT professionals (Pineda-Herrero et al., 2018). For instance, for employers, problem-solving is the most crucial skill for an IT specialist (Titko et al., 2016). Hence, HEIs need, as a primary challenge, to evaluate which educational innovations are essential to meet industry's needs (Hrmo et al., 2015) and by consequence to increase their awareness of the role that IT professionals play in economic competitiveness and social inclusion.

Recent literature has assessed the critical skills required for the new technological and digital paradigm and assumes that graduates will need to develop strong social skills, including communication, creativity, critical thinking and ethical values (Garcia-Esteban and Jahnke, 2020). Although technology advances require technical skills in employees, several studies highlight the role of cognitive skills, or the so-called "soft skills," in improving the professional profile of a worker (Garcia-Esteban and Jahnke, 2020). Nonetheless, students do not have clear and convergent information on what the job market expects, resulting in underdevelopment of the appropriate skills, as well as misguidance in their professional choices. Even though both company managers and students value the acquisition of IT skills, few recent studies have focused on how to achieve this and so to improve the employability of IT graduates (López-Pena et al., 2017; Titko et al., 2016).

Non-cognitive competencies appear to be critical skills for workforce qualification. In a future based on artificial intelligence decision-making, professionals with a background of dealing with social and emotional issues are increasingly valued. Employers have identified these competencies as the most important skills for the Industry 4.0 professional (Goulart et al., 2021). The labor market is being reformatted, and professionals and HEIs need to reinvent themselves to deal with the challenges imposed by the new demands.

Indeed, the IT job market and IT skills development are challenging issues for future generations. The IT job market becomes especially critical and complex when one considers the technological lag between developing and developed nations - a lag that may help explain why developing countries have trouble in transitioning to a more competitive economy (Hidalgo et al., 2007). Emerging countries need to pursue their technology capabilities for economic development (Whitley, 2002).

In this context, our primary goal is to evaluate the professional profiles expected by IT companies and IT departments in HEIs and the possible gap between them in an emerging country. Based on qualitative descriptive research, and by combining data from interviews with students and companies in Brazil, we explore this gap to advance understanding of the new professional skills related to the IT sector. We aim to contribute to novel studies of the IT and technology workforce by connecting the challenges of digitalization to human resource management, focusing on an emerging economy context.

There follows a theoretical background section in which we discuss the subject from the perspective of human resource management. We then explain the methodology and present the empirical results. Finally, we discuss the implications of the findings and present conclusions.

\section{New skills in the digital era}

The new technologies, digitalization and the automation of the workplace are changing how people do business, work and live. In the new 4.0 industrial and digital transformation, the effects of technological advances on the economy, society and the quality of life involve significant challenges for the job market (Valescu et al., 2020).

The continuous and exponential progress in digital and robotic technologies brings changes to and even the demise of jobs currently performed by humans (Ford, 2015; Spencer, 2018). Studies predict that many tasks will change dramatically and that many workers will have to adapt to the need for new skills (Spencer, 2018).

Digital technologies, as they replace older working methods, transform previously clearly-defined activities into more collaborative and complex tasks. The development of digital skills is critical for the effective use of human resources in the new digital era so that workers can adapt to changing work and processes (Kelchevskaya and Shirinkina, 2019).

According to Hecklau et al. (2016), organizational skills for the new technological paradigm can be divided into technical, methodological, social and personal. For Kinkel et al. (2017), the ability to build networks or solve highly complex problems related to innovation is a consequence of the application and development of organizational skills 
with a focus on the management of human resources. Erol et al. (2016) argue that, in a complex and changing environment, such as that of a technology-related industry, interdisciplinary guidance plays a vital role in supporting out-of-the-box thinking.

Higher education is a global source of innovation, policy, knowledge and assets (Ilori and Ajagunna, 2020). Its importance in the development of new professional skills is paramount (Kurbanov et al., 2020) and that function has implications for the principles of learning.

There is concern about the educational lag regarding new technologies and innovations, which are often not part of the curricula in HEIs (Ilori and Ajagunna, 2020). The lack of key employability skills has been a leading cause of unemployment (Dogara et al., 2019). Higher education needs to keep up with the pace of technological development, guaranteeing that the required technical and noncognitive skills will be developed in order to sustain future employment: jobs will be scarce for those without the required skills. HEIs need to be innovative with regard to their teaching and learning processes so that they can efficiently address the skills needs of the new technology job market (Ilori and Ajagunna, 2020).

A new generation of 4.0 managers will have to engage in complex processes of creating fundamentally new technologies and markets and modernizing the decision-making of existing industries in a climate of uncertainty, unpredictable change and considerable risk. Professionals will be responsible for a broader range of processes and will need to understand the relationships within processes, information connections, possible disruptions and potential solutions (Gitelman and Kozhevnikov, 2018).

Such increased scope and complexity will require a mindset geared toward building and maintaining networks of experts who can cooperate ad hoc in finding appropriate solutions to particular problems (Erol et al., 2016). Human tasks will focus on the boundaries of knowledge-intensive tasks, where flexibility in problem solving and creativity will be critical to competitiveness.

Digital transformation is driving change in higher education, not only in terms of teaching techniques but also in terms of the new skills that need to be taught, incorporating technical, managerial and non-cognitive capabilities that were not previously regarded as essential. Noncognitive skills or soft skills, in the era of digital transformation, have become critical skills for the professional who may now have a less significant operational role and a more prominent role in decision making, problemsolving and management (Dolce et al., 2020). Young managers, engineers and IT students need creative tools and techniques to acquire soft skills and so enhance their employability (Rao, 2014).

With the digital transformation, the workplace environment is not what it used to be (Ford, 2015). There is growing attention to its emotional and social aspects. Emotional intelligence, the ability to recognize, use and manage emotions, is a non-cognitive skill that has become essential in a variety of areas, including leadership, client relationships and decision-making. Paradoxically, such skills become even more critical as technologies move toward highly automated and digitized systems (Bay and McKeage, 2006).

Bailey (2014) studied the importance of knowledge, technical skills and non-technical skills in a prosperous professional environment, focusing on the IT industry. The motivation for his research was the need for an estimated 1 million new IT workers in 4 years and 1.4 million IT jobs by 2022 in the USA. He identified critical nontechnical skills in the IT industry to facilitate a responsive university curriculum for the coming years. Goulart et al. (2021) found that IT employers valued interpersonal skills such as reliability, leadership and empathy more than technical skills, while HEIs valued "knowledge" as the most important skill.

The idea that social and emotional skills can positively affect professional performance has spurred researchers to examine the importance of non-cognitive skills as learning goals (Cherniss and Adler, 2000; Cunningham and Villasenor, 2016; Heckman and Rubenstein, 2001; Urdinola and Gukovas, 2018). We can frame the broad construct of social and emotional competences into two domains: intrapersonal and interpersonal skills (Cherniss and Adler, 2000; Garner, 2010; Salovey and Mayer, 1990). Intrapersonal skills (e.g., realistic goal setting, positive mindset, self-control, emotional regulation and coping strategies) are necessary for effective behavior. Interpersonal skills (e.g., listening, communication, perspective taking, negotiation and social problem solving) are needed to interact with others.

The focus on social and emotional skills has emerged in the context of the Information Age. More services and speed in communication demand stronger abilities to deal with problems and solve them assertively (Cunningham and Villasenor, 2016; Dreyfus and Dreyfus, 1986; Urdinola and Gukovas, 2018). The soft skills identified in the literature as the most critical for Industry 4.0 and the technology industry specifically are teamwork, creativity, problem-solving, negotiation and communication, flexibility, the ability to cope with deadlines and social pressures, and analytical, interdisciplinary and systemic thinking (Erol et al., 2016; Hecklau et al., 2016).

Social and emotional learning is the process through which social and emotional competences develop. Through this process it is possible to acquire and effectively apply the knowledge, attitudes and skills necessary to understand and manage emotions, set and achieve positive goals, feel and show empathy for others, establish and maintain positive relationships, and make responsible decisions (Garner, 2010). 
It may be tempting to create a list of soft skills to enhance employability, but what matters is how these skills will be embedded in a continuous and transformative process during which individuals learn to recontextualize them to suit different activities and environments (Fettes et al., 2020). Recent studies have investigated how a collaborative learning environment can be used to develop soft skills and to what extent external stakeholders can become involved in the development of curriculum content (Samkin and Keevy, 2019). Pedagogical strategies to develop soft skills in universities, which are usually used to foster the commitment of students to activities, can benefit from their integration with the job market (Mareque et al., 2019) - that is, the education system must ensure the adequate teaching of soft skills for the employability of students (Dogara et al., 2019) in the changing future of jobs (Peters, 2020).

HEIs have an especially critical role in addressing technology-related unemployment in emerging countries. The lack of qualified labor and its consequence in terms of unemployment are critical issues in these economies (Bashir, 2007). Unemployment, strongly associated with low-quality higher and technical education, is one of the most severe causes of poverty in developing countries (Sevilla and Farias, 2020). For these economies, technology and innovation are critical factors for accelerating development. Having a labor force that is prepared for the challenges of Industry 4.0 has to be a priority for HEIs in these countries: at present, despite a growing labor market, there is a lack of prepared professionals with the new skills required (Goulart et al., 2021).

However, although HEIs in emerging economies have a vital role to play in addressing this problem, they tend to be dysfunctional, acting as certifiers of expertise rather than as institutions with the social purpose of qualifying professionals both technically and as citizens (Caplan, 2018). The effect of this failure is especially alarming in the case of technology education. For example, in Brazil a 2018 report noted that of 584,000 available positions in the technology job market, 252,000 were fulfilled, with $57 \%$ of the positions remaining open due to the lack of the necessary skills (Censup, 2018). HEIs need to develop a workforce that can address the needs of digital transformation and Industry 4.0 (Blackler and Orbone, 2003; Goulart et al., 2021).

\section{Methodology}

The study followed a qualitative approach using data acquired from interviews, focus groups and secondary sources. Data crossing employs multiple data sources in an attempt to describe a phenomenon better, removing the biases of a single method that may lead to a nonrepresentative result (Figaro, 2014; Yin, 2015).
We first used secondary data to analyze the curricula of different IT courses in a developing country. We then used primary data to identify and analyze the job profiles and skills required by large companies in the IT sector. Finally, data were collected from focus groups, through which we sought to understand students' perception regarding their employability, the qualification process and skills development in IT programs in HEIs. We also interviewed 10 human resource managers from IT companies and examined 13 course curricula of the top five HEIs in Brazil. We then invited 20 students from different Brazilian HEIs to participate in two focus group meetings to obtain feedback on our qualitative data collection.

We transcribed the interviews and structured our analysis using the following categories of qualitative information: the required skills and professional profile envisioned by the companies; the objective of the course and the profiles of alumni; and the benefits of professional student development. We used content analysis to navigate through the data and to contextualize the issue under study (Bardin, 2009).

We coded interview excerpts into research categories. Those that included the terms "teamwork" or "group work," for example, were coded as collaborative work skills, "out of the box" as creativity, and "ability to transfer messages" as communication skills.

We defined categories by content elements grouped by their relatedness (Bardin, 2009), separating them into analytical categories of skills. We used a mixed approach as follows. We first selected the potential categories, and then changed them according to their function in the overall analysis. A set of categories should be pertinent, as exhaustive as possible, not excessive, precise and mutually exclusive (Caregnato and Mutti, 2006). To complete the categorization, we performed a final analysis to reconsider and allocate the content. We performed an iterative and cyclical process, typical of qualitative research. We considered it most useful to classify the categories one by one, considering different ways of verbally expressing the same concept from that used by the interviewees.

\section{Results}

In this section, we describe the qualitative data from the empirical research. We synthesized the interviews with managers, and then also synthesized the results of the research into the documentation of HEI curricula and the responses of the IT student focus groups.

The managers confirmed a misalignment between higher education and the job profile required by the market. They indicated a lack of integration between educational institutions and companies. One manager said that, with a few exceptions, there was usually alignment between 
companies and HEIs only when the HEIs' students took the initiative to improve their education.

When asked about possible reasons for the lack of coordination between academic education and the needs of the market, the managers noted that the students' education was failing not only to train them in new technologies but to develop them as citizens able to contribute to society:

We need skills regarding programming, knowledge of codes, databases, project management, understanding of processes but the professionals need to have ethics, social responsibility.

\section{The managers affirmed that:}

Specific knowledge to fit an occupation is something usual. We expect the HEIs to go beyond, offering a humanistic development to help address a more just and equal society.

One interviewee declared:

In a world mediated by technologies and in a country where there are still regions where electricity has not even arrived, IT, as well as other areas, must prioritize social development through a fairer and more inclusive economy.

Humanist and social skills were also highlighted in two other responses: "We need awareness of respect, professional ethics, and critical sense"; "There is the need for innovation in mindset and broad vision (technical, management, emotional)."

Aside from programming skills, which represent the development of technical skills, all the other critical skills come into the category of non-cognitive or soft skills. The managers confirmed that these skills were what distinguished the excellent IT professional of today.

The managers thought that educational curricula overemphasized technical knowledge, but in a weak sense because the teaching of logic, algorithms and programming was not focused on problem-solving. Most of the interviewees pointed out the lack of experience in students of dealing with a professional environment, relating to other areas and delivering high-quality work to a deadline. They also noted that students had difficulties in communicating with less technical colleagues ("extreme difficulty in interacting with less technically educated staff").

Managers were more interested in personal, emotional and social characteristics than in technical abilities. Only two chose technical knowledge as the first required characteristic. One even considered ethics to be the first characteristic sought by the company. Other interviewees highlighted social and behavioral characteristics, innovation, commitment and promptness in problem solving as the primary needs of their company.

The last question put to the managers was whether they thought new graduates were prepared to perform organizational tasks. Some interviewees mentioned the need to diversify communication skills and others the need to "get out of the box." One manager used a strong image: "Yes, nowadays, they are well-trained robots." Others thought that a lack of persistence and commitment was the leading cause of bad performance.

In summary, the managers believed that the primary deficiency lay in the lack of personal and social skills development and the underdevelopment of innovative technical training and management skills. The following comments are representative:

Teaching is focused on usual market techniques, but they do not teach professionals to have a broad and critical view of problems and possible solutions; the result is that students come to the market only concerned with technical dimensions.

Students are motivated but they do not seem to understand what is demanded of them; even simple activities require a manager to sit and teach. This was supposed to be learned in the HEI.

They cannot think by themselves how to prioritize tasks. Sometimes we have a critical situation and the interns are dedicated to regular tasks.

I expect my employees to seek solutions, not wait for someone to tell them what to do. But that is exactly what we go through with them.

From the interviews with these HRMs from IT companies, the lack of alignment between IT higher education and the IT job market was apparent.

After the interviews, the managers were asked what were the critical skills for an excellent IT professional. Overall, they identified the primary skills as: entrepreneurial vision, creative ability, holistic vision, a focus on collaboration, codes and programming, ethics and social responsibility.

In the documentation phase of our research, we looked into the curricula of the three top IT-related degree courses from the Enade (2016) ranking, which includes Computer Engineering, Computer Science, Information Systems, Systems Analysis and Development, and Information Management.

In general, HEIs do not present any educational goals related to the development of soft skills in students, or at least they do not formally exhibit such initiatives. They do not present discussion concerning the expected behavior of the professional and offer scant information on the employment market and alumni profiles. Private institutions document their partnerships with large IT companies as well as internship and work placement opportunities, whereas public institutions are more inclined to highlight scientific initiatives, international mobility and engagement in community service projects.

Computer Engineering schools tend to focus more on technical skills and less on social and emotional skills. Two 
Table I. Average scores indicating the approach to soft skills in the educational curricula examined.

\begin{tabular}{lccccc}
\hline Entrepreneurial vision & $\begin{array}{c}\text { Creative } \\
\text { ability }\end{array}$ & $\begin{array}{c}\text { Holistic } \\
\text { vision }\end{array}$ & $\begin{array}{c}\text { Focus on } \\
\text { collaboration }\end{array}$ & $\begin{array}{c}\text { Codes and } \\
\text { programming }\end{array}$ & $\begin{array}{c}\text { Ethics and social } \\
\text { responsibility }\end{array}$ \\
\hline 0.23 & 0.23 & 0.23 & 0.3 & 0.61 & 0.15 \\
\hline
\end{tabular}

exceptions may be noted. One of the schools analyzed, a federal institution, offers a pedagogical project that deals intensively with socio-emotional skills. In this case, a reasonable amount of information is given but there is no detail on the teaching and learning methods that are being used to develop these skills. Another school offers optional content, enabling students to choose the outline of the course within a portfolio of disciplines ranging from arts to astronomy.

A careful content analysis of the curricula revealed that they would provide a solid technical-scientific background and professional training that should enable students to absorb and develop new technologies. In general, we found an absence of content related to socio-emotional skills of any kind and great emphasis on technical knowledge and theoretical training.

We then compared the skills identified by the IT managers with the content of the educational curricula. The level of approach to each skill was measured on a simple scale from 0 to 3 , with 0 indicating that soft skills are not mentioned in the curriculum; 1 that there is a superficial mention of soft skills (we took into consideration the use of synonyms to identify such skills); 2 that there are mentions of soft skills and discussion concerning their application but nothing about teaching and learning activities related to such skills; and 3 that soft skills are mentioned along with related teaching and learning activities.

Table 1 presents the average of the scores for the approach presented in the curricula to the soft skills identified by the managers. Skills that were not highlighted by the managers reached an average of at least 1 in the scale: an exception was codes and programming, which scored 3 in one of the courses analyzed. The standard educational curriculum does not present any information on soft skills, and so the average is at a low level. In general, the schools do not formally express their commitment to any social or emotional development of the IT professional. The skill that appeared the most was codes and programming ability, and the one that appeared least was ethics and social responsibility. Other skills mentioned to some extent included holistic vision, a focus on collaboration, entrepreneurial vision and creative ability.

After analyzing the data from the course curricula, we interviewed two focus groups of students, with 10 in each group.

Students from both groups reported and discussed the dynamism of the IT job market, explaining how they felt about the constant change driven by technological development. This dynamic nature of the job market implies that there will fewer available positions for senior professionals and more work availability for recent graduates. Thus this reality facilitates the entry of young people into the job market, while at the same time restricting mobility between companies and salary improvement.

The students thought, in general, that their higher education was insufficient to prepare them for the job market. They felt that they had acquired a good basis of knowledge, with general and theoretical content. They said that, from that basis of knowledge, all responsibility for learning was theirs, noting their own role in the development of their career. In addition, the students noted the absence of practical activities in the curriculum, which left companies with the responsibility of completing the education of graduate recruits.

The groups also discussed the job market and the need for more significant interaction between HEIs and professionals. There was a clear perception of a gap between market needs and what was offered in their professional development. They pointed out that companies became main training institutions for students who arrived with skills below the level desired by the market.

Most students indicated that was no institutional support from HEIs at the beginning of the professional internship. They reported that some teachers encouraged students to bring real cases from their work experience to be discussed in the classroom, but they perceived this more as a methodology for teaching in the classroom than as a support for the internship.

When asked whom students consulted when facing difficulties in their apprenticeships, they affirmed that there were few specific teachers they could count on, and sometimes they sought support from senior colleagues: "The teacher is a mentor of professional life. He is the person you will turn to." Some felt that this support was fundamental to their professional growth.

A few students from a specific institution declared that they had developed "professional-life projects" on their course. They had classes guided by mentoring teachers to help them shape their careers. However, when asked if they had received any help in developing their professional career project, most said they had not received such support.

Regarding the soft skills identified by the company managers, the students thought that codes and programming and entrepreneurial vision were the most important for their professional career. Also, they reported that soft skills 
were desirable in any professional conditions and added value to employability. They considered that HEIs and employers were both responsible for training in such skills and shared an equal influence on their qualification.

Students rated ethics and responsibility, creative ability and a focus on collaboration as very important, whereas holistic vision was considered less important by most. They saw the development of these soft skills as fundamental and emphasized the lack of contribution of HEIs in this respect. Thus we find that HEIs are not considered protagonists in developing soft skills in students and that this shortcoming directly impacts their perception of what constitutes qualification for the job market.

For students the greatest gap that hinders their success in the job market relates to a lack of ways to reproduce the corporate environment: "We know what to do but we do not know how, when and why"; "We have problems understanding how to behave in a meeting, what people expect from us." Other comments included:

We learn how to work in the internship and it is totally different from what the classroom can teach us.

When we are only studying there is no need to relate to an intense matter, students can shape the way they dedicate themselves to exercises and lessons. In the job environment we do not have the choice.

Things change fast in the daily activities of a firm. In a classroom situation everything is programmed and changes are less common.

\section{Discussion}

There is misalignment between the professional profile required by IT companies and what is taught in HEIs. Managers seek professionals with technical and social skills, especially those prepared for problem-solving approaches. They consider graduates as immature and with deficits in both technical and soft skills. HEIs, according to our assessment of curricula, reinforce the concept of quality in their courses by providing significant technical content. Among the skills identified by managers, the most technical (codes and programming) was the most prevalent in the curricula. On the other hand, students try to build their own careers, accommodating job-market requirements and the technical content they are taught in HEI courses.

The companies highlighted that the main challenge in dealing with undergraduates was to adapt the young professionals to the workplace, especially with regard to practical solutions. The managers believe that education should develop a more holistic approach, broadening horizons to avoid the production of "well-trained robots." Technical skills were also seen as critical, but there was an emphasis on soft skills. This perception aligns with the literature, which argues that technical and personal skills are both fundamental for individual development but emphasizes that the latter represent a differentiating factor in the performance of professionals who face the challenges of a changing environment in the digital era (Dogara et al., 2019; Fettes et al., 2020). According to the managers interviewed, people with these skills are difficult to find, reinforcing that a skill-based approach must take into account the integration of cognitive, motivational and affective intellectual processes that characterize any human action.

In this sense, the IT curricula of HEIs and the primary skills identified by managers are in opposition. The HEIs analyzed are geographically concentrated in southeastern and southern Brazil and are public and private institutions of excellence. Although one can find exciting initiatives to stimulate soft skills on the websites of the HEIs, such as laboratories, interdisciplinary activities and mandatory internships, there is a clear emphasis on technical knowledge, such as programming languages and networks. Among the curricula investigated, only one makes direct reference to an innovative teaching methodology and proposes active and problem-solving methodologies. It seems that the information presented on these websites attempts to align with student expectations rather than detailing training practice. The most frequently mentioned skill in the descriptions of curricula of those highlighted by the managers is codes and programming, and the least frequent was ethics and responsibility. Other soft skills were occasionally cited - such as holistic vision, a focus on collaboration and creative ability.

The disappointment of the students with the education they had received was also evident. They considered their courses generalist and disconnected from the reality of the market. They claimed that they had to seek complementary training to fit the needs of companies, which often took over the responsibility of improving their qualification and thus ended up completing the professional development of young professionals and assuming a role that should be played by HEIs. Students noted that was no institutional support in their early period of internship; the HEIs do not directly assist them to enter the job market, and especially in the development of their professional careers. In general, students value the trust they have in their professors, but on the other hand they complain about the excessive autonomy that professors have with regard to teaching methods, which can promote inconsistency and consequently learning difficulties.

In summary, the training of IT professionals should be based on skills that make sense in the current digital era and addressing the needs of companies. The employability of IT graduates is not limited to technical skills; indeed, studies and empirical results reveal that soft skills are what differentiates highly-qualified IT professionals in the job market. HEIs should seek to develop in their students the ability to make decisions and to adapt to new situations, oral and written communication skills, 
teamworking social skills and collaboration skills. Professionals are increasingly valued for their ability to manage their own emotions, establish positive relationships, take responsibility for their actions and safeguard the ethical performance of the company.

\section{Conclusions}

We conclude that there is a significant gap between the professional profile required by IT companies and that shaped by HEIs. This finding is supported by the empirical data analyzed through the crossing of data from interviews with IT managers, student focus groups and an analysis of IT-related curricula.

The results corroborate those of previous studies of human resource management in digital transformation and the future of work (Ahuett-Garza and Kurfess, 2018; Calitz et al., 2017; Hecklau et al., 2016; Kergroach, 2017; Kinkel et al., 2017). The current higher education system is failing in its primary objective of developing professionals with the skills demanded by the job market. More than that, it fails to provide an education that addresses social and emotional skills as well as technical skills and thus incorporates humanistic and non-cognitive education.

This failure highlights the complex challenge of developing a qualified workforce for the employment requirements of the digital era, affecting all technology-dependent industries to survive in competitive markets. A root cause is the distance between HEIs and the market: the empirical data presented provide evidence of the inadequate relationship between IT companies and HEIs, which has resulted in a lack of success in the provision by HEIs of suitably qualified professionals. Beyond the development of soft skills in students, HEIs need also to seek a new management paradigm based on solid relationships with the market and a multi-stakeholder strategic approach.

As a contribution to human resource theory, our results identify a set of skills to be incorporated into the job profiles of the future, closely related to the digital transformational era. The study allowed us to understand the critical role of the humanistic perspective in education and the need, as technology unfolds and develops, for professional qualification to rise above technical aspects. The primary skills identified by this study were entrepreneurial vision, creative ability, holistic vision, a focus on collaboration, codes and programming and ethics and social responsibility.

The study also indicated, corroborating the findings of previous studies (Pineda-Herrero et al., 2018), that HEIs have a fundamental role in guiding the development of a professional career plan for students, focusing on their background, employment choices and opportunities. However, our empirical data show that HEIs are not yet committed to this approach of helping students develop long-term career planning.
From these results, we can confirm that there is a lack of coordination between the skills required by the job market and those developed by HEIs in the Brazilian IT sector. HEIs also do not provide students with guidance on their socio-emotional skills and do not provide precise mechanisms for supporting the development of the skills identified as crucial.

As a qualitative work, our results are limited with regard to their generalization to other countries and sectors. Other emerging countries, however, because of their nature, may present similar conclusions.

This study highlights the critical role of HEIs in the professional development plan of students. For future study, we suggest discussion of the Adaptive Work Life Project (AWLP) proposed by Jáuregui (2015) as a potential instrument for increasing productivity and driving the development of soft skills.

\section{Declaration of conflicting interests}

The author(s) declared no potential conflicts of interest with respect to the research, authorship, and/or publication of this article.

\section{Funding}

The author(s) received no financial support for the research, authorship, and/or publication of this article.

\section{ORCID iD}

Luciana Oranges Cezarino (D) https://orcid.org/0000-0001-55568275

\section{References}

Ahuett-Garza H and Kurfess T (2018) A brief discussion on the trends of habilitating technologies for Industry 4.0 and Smart manufacturing. Manufacturing Letters 15: 60-63.

Bailey JL (2014) Non-technical skills for success in a technical world. International Journal of Business and Social Science 5(4): 1-10.

Bardin L (2009) Content Analysis. Lisboa: Editions, 70.

Bashir S (2007) Trends in international trade in higher education: implications and options for developing countries. Education Working Paper Series, Number 6. Washington DC: World Bank Publications.

Bay D and McKeage K (2006) Emotional intelligence in undergraduate accounting students: preliminary assessment. Accounting Education 15(4): 439-454.

Blackler F and Orbone D (2003) Information Technology and People: Designing for the Future. Cambridge, MA: MIT Press.

Calitz AP, Poisat P and Cullen M (2017). The future African workplace: The use of collaborative robots in manufacturing. SA Journal of Human Resource Management 15(1): 1-11.

Caplan B (2018) The Case Against Education: Why the Education System Is a Waste of Time and Money. Princeton, NJ: Princeton University Press. 
Caregnato RCA and Mutti R (2006) Pesquisa qualitativa: análise de discurso versus análise de conteúdo. Texto \& ContextoEnfermagem 15: 679-684.

Censup - Censo da Educação Superior (2018) Available at: http:// portal.inep.gov.br/web/guest/microdados (accessed 28 February 2018).

Cherniss C and Adler M (2000) Promoting Emotional Intelligence in Organizations: Make Training in Emotional Intelligence Effective. Washington DC: American Society of Training and Development.

Cunningham W and Villasenor P (2016) Employer voices, employer demands, and implications for public skills development policy connecting the labor and education sectors. World Bank Research Observer 31(1): 102-134.

Dogara G, Bin Saud MS, Bin Kamin Y, et al. (2019) Developing soft skills through project-based learning in technical and vocational institutions. International Journal of Recent Technology and Engineering 8(3): 5872-5877.

Dolce V, Emanuel F, Cisi M, et al. (2020) The soft skills of accounting graduates: perceptions versus expectations. Accounting Education 29(1): 57-76.

Dreyfus HL and Dreyfus SE (1986) Mind Over Machine: The Power of Human Intuition and Expertise in the Era of the Computer. New York, NY: The Free Press.

Exame Nacional de Desempenho dos Estudantes (Enade). Available at: https://www.gov.br/inep/pt-br/areas-de-atuacao/avalia cao-e-exames-educacionais/enade

Erol S, Jäger A, Hold P, et al. (2016) Tangible Industry 4.0: a scenario-based approach to learning for the future of production. Procedia CIRP 54: 13-18.

Fettes T, Evans K and Kashefpakdel E (2020) Putting skills to work: it's not so much the what, or even the why, but how. Journal of Education and Work 33(2): 184-196.

Figaro R (2014) A triangulação metodológica em pesquisas sobre a Comunicação no mundo do trabalho. Fronteiras-estudos midiáticos 16(2): 124-131.

Ford M (2015) The Rise of the Robots: Technology and the Threat of Mass Unemployment. London: Oneworld Publications.

Garcia-Esteban S and Jahnke S (2020) Skills in European higher education mobility programmes: outlining a conceptual framework. Higher Education, Skills and Work-Based Learning 10: 519-539.

Garner PW (2010) Emotional competence and its influences on teaching and learning. Educational Psychology Review 22: 297-321.

Gitelman L and Kozhevnikov M (2018) Paradigm of managerial education for a technological breakthrough in the economy. Economy of Region 1(2): 433-449.

Goulart AR, Liboni LB and Cezarino LO (2021) Qualification as a societal challenge and the role of higher education from a system approach. Higher Education, Skills and Work-Based Learning. Epub ahead of print 8 February 2021. DOI: 10. 1108/HESWBL-06-2020-0118.
Hecklau F, Orth R, Kidschun F, et al. (2016) Human resources management: meta-study-analysis of future competences in Industry 4.0. In: Proceedings 13th European Conference on Management Leadership and Governance (ECMLG). London: ACPI, pp. 163-174.

Heckman J and Rubenstein Y (2001) The importance of noncognitive skills: lessons from the GED testing program. American Economic Review 91(2): 145-149.

Hidalgo CA, Winger B, Barabási A, et al. (2007) The product space conditions the development of nations. Science 317(5837): 482-487.

Hrmo R, Kristofiakova L and Mistina J (2015) Building a quality system of technical and vocational education in Slovakia towards a European labour market. In: Proceedings of 2015 international conference on interactive collaborative learning, ICL 2015, pp. 237-243. DOI: 10.1109/ICL.2015.7318032. Available at: www.scopus.com (accessed March 2019).

Ilori MO and Ajagunna I (2020) Re-imagining the future of education in the era of the fourth industrial revolution. Worldwide Hospitality and Tourism Themes 12(1): 3-12.

Jáuregui IP (2015) El Proyecto de Vida Laboral. Universidad Del Salvador.

Kelchevskaya NR and Shirinkina EV (2019) Regional determinants of effective use of human capital in the digital economy. Economy of Region 15(2): 465-482.

Kergroach S (2017) Industry 4.0: new challenges and opportunities for the labour market. Foresight and STI Governance 11(4): 6-8.

Kinkel S, Schemmann B and Lichtner R (2017) Critical competencies for the innovativeness of value creation champions: identifying challenges and work-integrated solutions. Procedia Manufacturing 9: 323-330.

Kurbanov RA, Belyalova AM, Yarygina NA, et al. (2020) Student attitude to future profession in field of information technology at university training stage. International Journal of Psychosocial Rehabilitation 24(4): 5019-5026.

López-Pena V, López-Chao V and Ramiro-Aparicio D (2017) A study of the IT competence training in technical drawing in higher education. Paper presented at the ACM International Conference Proceeding Series, Part F132203. DOI: 10.1145/3144826.3149547. Available at: www.scopus.com (accessed March 2019).

Mareque M, de Prada Creo E and Gonzalez-Sanchez MB (2019) Fostering creativity and communicative soft skills through leisure activities in management studies. Education and Training 61(1): 94-107.

Peters MA (2020) Beyond technological unemployment: the future of work. Educational Philosophy and Theory 52(5): 485-491.

Pineda-Herrero P, Ciraso-Cali A and Armijos-Yambay M (2018) Employable and competences of pedagogy, psychology, and educational psychology graduates: a comparative study of employers and graduates [Competencias para la empleabilidad de los titulados en Pedagogía, Psicología y Psicopedagogía: Un estudio comparativo entre empleadores y titulados]. Revista Espanola De Pedagogia 76(270): 313-333. 
Rao MS (2014) Enhancing employability in engineering and management students through soft skills. Industrial and Commercial Training 46(1): 42-48.

Salovey P and Mayer JD (1990) Emotional intelligence. Imagination, Cognition, and Personality 9: 185-211.

Samkin G and Keevy M (2019) Using a stakeholder developed case study to develop soft skills. Meditari Accountancy Research 27(6): 862-882.

Sevilla M and Farías M (2020) Labour market mismatch in emerging countries: the case of Chile. Compare 50(2): 276-293.

Spencer DA (2018) Fear and hope in an age of mass automation: debating the future of work. New Technology, Work and Employment 33(1): 1-12.

Titko J, Smatkova I and Cerkovskis E (2016) Demand for IT students in Latvian labour market: viewpoint of employers. In: Proceedings of the 28th International Business Information Management Association conference-Vision 2020: innovation management, development sustainability, and competitive economic growth, pp. 1812-1823. Available at: www.scopus.com (accessed February 2019).

Urdinola DFA and Gukovas RM (2018) Skills-based human capital framework to understand the phenomenon of youth economic disengagement. Education global practice \& social protection and labor global practice. Policy Research Working Paper 8348, February. Washington DC: World Bank.

Vasilescu MD, Serban AC, Dimian GC, et al. (2020) Digital divide, skills and perceptions on digitalisation in the European Union-towards a smart labour market. PLOS ONE 15(4): e0232032.

Whitley R (2002) Developing innovative competences: the role of institutional frameworks. Industrial and Corporate Change 11(3): 497-528. Available at: www.scopus.com (accessed February 2019).

Yin RK (2015) Estudo de Caso-: Planejamento e métodos. Bookman editora. 